MANEL TERRAZA ${ }^{1}$

E-mail: manel.terraza@gmail.com

JI ZHANG ${ }^{2}$

Email: jzhan121@hawk.iit.edu

ZONGZHI LI, Ph.D. ${ }^{2}$

(Corresponding author)

E-mail: lizz@iit.edu

${ }^{1}$ Department of Civil Engineering

Universitat Politècnica de Catalunya

Barcelona, Spain

2 Department of Civil, Architectural and Environmental

Engineering

Illinois Institute of Technology

Chicago, IL 60616, USA
Traffic Engineering

Original Scientific Paper

Submitted: 4 Sep. 2020

Accepted: 12 Feb. 2021

DOI: $10.7307 /$ ptt.v33i4.3694

\title{
INTERSECTION SIGNAL TIMING OPTIMISATION FOR AN URBAN STREET NETWORK TO MINIMISE TRAFFIC DELAYS
}

\section{ABSTRACT}

The ever-increasing travel demand outpacing available transportation capacity especially in the U.S. urban areas has led to more severe traffic congestion and delays. This study proposes a methodology for intersection signal timing optimisation for an urban street network aimed to minimise intersection-related delays by $d y$ namically adjusting green splits of signal timing plans designed for intersections in an urban street network in each hour of the day in response to varying traffic entering the intersections. Two options are considered in optimisation formulation, which are concerned with minimising vehicle delays per cycle, and minimising weighted vehicle and pedestrian delays per cycle calculated using the 2010 Highway Capacity Manual (HCM) method. The hourly vehicular traffic is derived by progressively executing a regional travel demand forecasting model that could handle interactions between signal timing plans and predicted vehicular traffic entering intersections, coupled with pedestrian crossing counts. A computational study is conducted for methodology application to the central business district (CBD) street network in Chicago, USA. Relative weights for calculating weighted vehicle and pedestrian delays, and intersection degrees of saturation are revealed to be significant factors affecting the effectiveness of network-wide signal timing optimisation. For the current study, delay reductions are maximised using a weighting split of 78/22 between vehicle and pedestrian delays.

\section{KEY WORDS}

urban network; intersection; vehicle delay; pedestrian delay; signal timing; optimisation.

\section{INTRODUCTION}

\subsection{Background}

The population growth and economic development have resulted in travel demand increase, especially in urban areas. With the pace of transportation capacity expansion falling significantly behind the level of travel demand escalation, many urban street networks in the United States are currently operated close to, or even over capacities in the AM and PM peak periods. Owning to land scarcity in urban areas and prohibitively high costs of facility delivery, expanding the capacity of an urban street network is typically not feasible. The ever-increasing gap of capacity shortage in the urban street network has then exacerbated recurrent urban traffic congestion in peak periods that is increasingly becoming one of today's biggest challenges. To slow down the deteriorating trend of urban traffic conditions, improving the utilisation efficiency of the existing capacity of an urban street network has been gradually thought of as a possible solution $[1,2]$. One of the related measures is to reduce delays experienced by individual travellers at intersections that are affected by intersection signal timing plans deployed in the urban area.

In the last several decades, extensive research has been conducted to develop methods and models to estimate intersection delays and identify effective means to mitigate such impacts. For example, Koutsopoulos and Habbal [3] studied how 
different methods for calculating vehicle delays at intersections affect results obtained from a traffic assignment model. These researchers used the 1985 Highway Capacity Manual (HCM) method for impacts assessment based on four scenarios with different levels of details on intersection geometry designs and traffic control. It was concluded that the 1985 HCM procedure worked well and, although increased details of geometric designs and traffic control could reduce errors significantly, the computational intensity became drastically increased. Thus, adopting a simple but practical model for intersection delay estimation would be desirable when conducting a large-scale network analysis. Fambro and Rouphail [4] proposed an improved approach over the 1994 HCM method for calculating intersection delays that formed the basis of the $2010 \mathrm{HCM}$ method. It incorporates one more term in the delay equation to handle traffic-actuated control and effects of upstream signals, along with additional parameters inside the equations to enhance the accuracy of delay estimation in oversaturated traffic conditions. The enhanced model was verified using both field and simulated data. Aashtiani and Iravani [5] developed a method to calculate vehicle delays at signalised intersections in the city of Tehran, Iran. Specifically, the Webster equation was integrated into the EMME/2 software to iteratively compute the cycle length and green splits using the predicted traffic volumes with model validation by field traffic counts as inputs, followed by vehicle delay calculation $[6,7]$. The main feature of the proposed method is the low amount of input data needed, which makes it a decent choice for adoption in cities where fine-grained data is not available. Liu et al. [8] proposed a method for delay calculation by categorising intersection traffic into undersaturated, near saturated, and oversaturated conditions. Each traffic condition was further separated as the presence and absence of an initial queue at the intersection. The method first focused on deriving the delay formula for each of the six cases and then on an application to three-phase signalised intersections. Two types of intersection utilisation cases were studied where all intersection approaches were undersaturated and all approaches were conversely oversaturated. Further refinements were made to cover mixed cases of having some intersection approaches undersaturated and the remaining approaches oversaturated to match real-world situations more closely.

Mazloumi et al. [9] introduced a formula to calculate intersection delays in a traffic assignment model addressing impacts of driver behaviour. The formula demands modest data inputs, making it very useful for real-life traffic assignments. As the HCM hypothesis on intersection delays could not be assumed in Iran, these researchers proposed a new formula and compared the results and its adjustments to reality with the HCM model. This formula and the HCM model were then introduced to a traffic assignment model to generate traffic flow predictions. When compared to field traffic data in the city of Mashhad, Iran, a better goodness of fit was obtained from the proposed formula for delay estimation. It was concluded that the specific circumstances of different countries would affect the nature of intersection delays, implying that the formula for calculating delays be adjusted accordingly.

Wolshon and Taylor [10] analysed changes in intersection delays when applying a time responsive signal control strategy introduced by Lowrie [11] as part of assessing the hypothesised effectiveness of real-time signal control compared with the pre-timed control. This analysis was applied in six intersections in the city of South Lyon, France. To facilitate cross comparisons of the two strategies, a formula was introduced to calculate intersection delays. The results showed that vehicle delays are distributed more evenly across intersection approaches in the application of the SCATS system. However, it could lead to increase of total intersection delays in some cases. Quiroga et al. [12] also proposed a model for calculating intersection delays. For the model application, global positioning system (GPS) devices were installed in several vehicles to collect precise data on vehicle deceleration, acceleration, and stopped delay times. These researchers identified a linear relationship between delays and rates of vehicle deceleration and acceleration manoeuvres.

Li et al. [13] proposed a new model for computing intersection delays through image processing. It is the first research that utilised the image processing technique to calculate intersection delays without having problems of dealing with overlapping images of vehicles and the need for model calibration before being adopted for predictive 
analysis resembles that of a simulation model. An algorithm was developed to effectively detect and track vehicles using two camera-based detectors, one at upstream of an intersection and the other at the stop line. The delay of each vehicle was calculated as the difference between the time a vehicle passes the stop line at the downstream intersection and the time for the vehicle traversing through the same distance at a free-flow speed. Results were compared with field data to verify the accuracy and precision of the proposed method, showing the usefulness of the algorithm in real-time application due to low time consumption.

Zhu et al. [14] proposed a real-time network model for vehicle navigation applications incorporating intersection delays. The significance of this model is in that it not only includes intersection delays that many researchers do not consider or treat them as a constant if considered, but also re-optimises vehicle paths as new information becomes available. The model includes an augmented Dijkstra algorithm where the optimal results are updated in response to the additional information. This model was tested in Chongqing, China with results of optimal travel paths obtained highly consistent with real-world choices. The model application is potentially limited to transportation agencies capable of collecting, processing, and analysing massive data for related model applications.

Qiao et al. [15] proposed a model for estimating intersection delays based on the fuzzy logic theory. The use of fuzzy logic allows to consider not only technical factors but also non-technical factors such as weather conditions that affect delays. Factors incorporated into the proposed model include flow ratio, green time, cycle time, and weather condition. The model was executed alongside with the Webster model and the HCM model to estimate intersection delays using field data collected in Hong Kong, China. The model estimation errors were found to be significantly lower than those of the Webster and HCM applications.

Some recent studies have concentrated on optimisation of intersection signal timing plans for an urban network. For instance, Roshandeh et al. [16] developed a model using the shockwave theory to design signal timing plans for intersections in an urban street network aimed to minimise vehicle delays experienced by travellers. In the proposed model, both vehicle and pedestrian delays have been incorporated into the optimisation formulation. This treatment is advantageous in presence of high pedestrian traffic in urban areas where shared mobility of vehicle and pedestrian traffic should be given duly cognisance in the intersection signal timing design.

\subsection{Motivation}

Travellers have experienced benefits of delay reductions from intersection signal timing optimisation following various methods gradually refined over the years. The refinements are manifested by the analytical capabilities in spatial and time dimensions concerning the extent of facility coverage and time fragmentation of signal timing designs. The facility coverage has been enlarged from an isolated intersection, intersections along one or more parallel corridors, to intersections of an entire network. As for the time fragmentation of signal timing designs, it has been expanded from peak and non-peak periods of a day, hour-by-hour, to virtually subhour intervals. Delay calculations have also been broadened from considering vehicular delays only to holistically addressing both vehicle and pedestrian delays. For instance, the model developed by Roshandeh et al. [16] is a typical case superior to many existing methods and models because it conducts signal timing optimisation for intersections in an urban network, considers mobility of both vehicle and pedestrian traffic, and derives optimal signal timing plans by minimising weighted vehicle and pedestrian delays where the relative weights of vehicle delays could be adjusted in the range of $10 \%-100 \%$ with a decrement of $10 \%$ in each option of weighting combinations. However, no attempt was made to identify the best weighting combination for vehicle and pedestrian delays in signal timing design. In this respect, it motivates a more thorough investigation into the use of widely adopted methods for estimating vehicle and pedestrian delays such as the HCM method and identification of the specific weighting combination for vehicle and pedestrian delays as the objective to be minimised. Intuitively, vehicle delays should have a higher relative weight as opposed to pedestrian delays since the mode share of travel by the auto mode and other private vehicle modes such as carpool, vanpool, and other types of ridesharing is typically predominant. Determining such a weight will help transportation planners and traffic operators design the truly 
optimal intersection signal timing plans to mitigate delays encountered by vehicle drivers and pedestrians utilising an urban street network.

\subsection{Outline}

The remainder of this paper is organised as follows: The next section describes the proposed methodology for determining the most favourable share of weights between vehicle and pedestrian delays for intersection signal timing optimisation. The subsequent section focuses on applying the proposed methodology in a computational study. Finally, the last section presents a study summary and draws conclusion.

\section{PROPOSED METHODOLOGY}

\subsection{Method for estimating intersection delays}

Since its inception, HCM has been widely used by transportation engineers for traffic operations analysis. For this reason, the current study employs the $2010 \mathrm{HCM}$ method [1] to estimate vehicle and pedestrian delays at individual intersections according to entering traffic and the adopted signal timing plans.

\section{Estimation of intersection vehicle delays}

According to the $2010 \mathrm{HCM}$ method, intersection-related vehicle delays are defined as average control delays experienced by all vehicles that arrive at an intersection for the duration of an analysis period. They generally consist of uniform delay, incremental delay owing to traffic fluctuation, and initial queue delay caused by vehicles unable to be released from the intersection in one or more previous signal cycles.

$d_{V E H, j, k, T}=d_{1, j, k, T}+d_{2, j, k, T}+d_{3, j, k, T}$

where:

$d_{V E H, j, k, T}$ - intersection control-related vehicle delays associated with approach $k$ of intersection $j$ during the analysis period $T$, in sec/veh, which are comprised of:

$d_{1, j, k, T} \quad$ - uniform delay;

$d_{2, j, k, T} \quad$ incremental delay;

$d_{3, j, k, T}-$ initial queue delay.

Uniform delay. Uniform delay is an estimate of delay assuming random uniform arrivals, stable flow, and no initial queue. It also assumes one effective green time during the cycle and one saturation flow rate during this period. Saturation flow rate is the equivalent hourly rate at which previously queued vehicles can traverse an intersection approach under prevailing conditions if the green signal is always available and no lost times are experienced. This means that a flow rate higher than the saturation flow rate will lead to a queue at the end of the cycle. The uniform delay of an intersection approach can be calculated as:

$d_{1, j, k, T}=\frac{0.5 \cdot C_{j} \cdot\left(1-\frac{g_{j}}{C_{j}}\right)^{2}}{1-\min \left(1, X_{j, k}\right) \cdot \frac{g_{j}}{C_{j}}} \cdot \frac{T}{C_{j}}$

where:

$C_{j}$ - cycle length designed for intersection $j$ to complete the signal sequence of green, yellow, and red intervals, in sec;

$g_{j}-$ effective green time available to perform vehicle movements in approach $k$ of intersection $j$, in sec;

$X_{j, k}-v_{j, k} / c_{j, k}$ as the volume-to-capacity ratio indicating how close to saturation in approach $k$ of intersection $j$ where $v_{j, k}$ and $c_{j, k}$ are traffic volume of the critical travel lane of approach $k$ of intersection $j$, in $\mathrm{veh} / \mathrm{h} / \mathrm{ln}$, and the maximum sustainable flow rate at which vehicles can be expected to drive through the intersection approach, in $\mathrm{veh} / \mathrm{h} / \mathrm{ln}$; $\min \left(1, X_{j, k}\right)$ - the lower value between 1 and $X_{j, k}$

Incremental delay. Incremental delay is the extra delay due to non-uniform arrivals and temporary cycle failures (random delay), as well as delay caused by sustained periods of oversaturation. Typically, the calculation assumes that there is no unmet demand causing initial queues at the start of the analysis period. Incremental delay contains two components: The first portion is associated to the fluctuations in demand during the cycle where demand might exceed capacity at some point. The second portion accounts for delay caused by a sustained oversaturation experienced by an intersection approach during the analysis period.

$d_{2, j, k, T}=900 T\left[\left(X_{j, k}-1\right)+\sqrt{\left(X_{j, k}-1\right)^{2}+\frac{8 K_{j} \cdot I_{j} \cdot X_{j, k}}{c_{j, k} \cdot T}}\right]$

where:

$K_{j}$ - the incremental delay factor to account for the effect of signal control type with a value of 0.5 recommended for pre-timed signals;

$I_{j} \quad$ - the upstream filtering/metering adjustment factor to handle the effect of metering arrivals 
for the upstream intersection to intersection $j$ with a value of 1.0 suggested for an isolated intersection.

Initial queue delay. The equation used for estimating incremental delay assumes that there is no initial queue in presence at the start of the analysis period. The initial queue delay accounts for the additional delay caused by an existing initial queue. This queue is the result of unmet demand in the previous period. The initial queue delay of an intersection approach is computed as:

$d_{3, j, k, T}=\frac{3600}{v_{j, k} \cdot T} \cdot\left(t \cdot \frac{Q_{b, j, k}+Q_{e, j, k}-Q_{e o, j, k}}{2}+\frac{Q_{e, j, k}^{2}-Q_{e o, j, k}^{2}}{2 c_{j, k}}-\frac{Q_{b, j, k}^{2}}{2 c_{j, k}}\right)$

with

$$
\begin{aligned}
& Q_{b, j, k}(h)=Q_{b, j, k}(h-1)+T\left(v_{j, k}(h)-c_{j, k}\right) \\
& Q_{e, j, k}=Q_{b, j, k}+t\left(v_{j, k}-c_{j, k}\right) \\
& Q_{e o, j, k}=\left\{\begin{array}{l}
T\left(v_{j, k}-c_{j, k}\right), t=T, \text { if } v_{j, k}>c_{j, k} \\
0, t=\frac{Q_{b, j, k}}{c_{j, k}-v_{j, k}}, \text { otherwise }
\end{array}\right.
\end{aligned}
$$

where:

$h$ - the period of calculation that typically lasts from one hour to 24 hours of a daily period;

$t$ - the adjusted duration of unmet demand in the analysis period requiring queue dissipation, in hour;

$Q_{b, j, k}$ - initial queue of approach $k$ of intersection $j$ at the start of the analysis period,

$Q_{e, j, k}$ - queue at the end of the analysis period;

$Q_{e o, j, k}-$ queue at the end of the analysis period due to oversaturation and without initial queue, in veh.

In contrast with calculating uniform and incremental delays by lane group that are averaged over different lane groups, initial queue delay is estimated directly for the entire intersection approach. This technical treatment is due largely to lack of information on the types of initial queues across different lane groups.

\section{Estimation of intersection pedestrian delays}

According to the $2010 \mathrm{HCM}$ method, the delays of pedestrians waiting to cross an intersection approach are computed as follows:

$d_{P E D, j, k, C_{j}}=\frac{\left(C_{j}-g_{W A L K, j, k}\right)^{2}}{2 \cdot C_{j}}$

where:

$d_{P E D, j, k, C_{j}}$ - the average pedestrian delay per pedestrian per cycle for pedestrians using approach $k$ of intersection $j$ during the cycle length period of $C_{j}$, in sec/ped/cycle;

$g_{W A L K, j, k}$ - the effective green time for pedestrians crossing approach $k$ of intersection $j$, in sec.

\subsection{Method for network-wide intersection signal timing optimisation}

Network-wide intersection signal timing optimisation could be carried out using two models, which include a base model focusing on minimising vehicle delays per vehicle per cycle, and an enhanced model aimed to minimise the weighted vehicle and pedestrian delays per traveller per cycle. The objective functions of the base and enhanced models have the following specifications:

Base model:

Minimise $d_{V E H} /$ cycle $=\left[\sum_{j=1} \frac{\sum_{k=1}^{K_{j}}\left(d_{V E H, j, k, T} \cdot \frac{C_{j}}{T}\right)}{K_{j}}\right] / J_{A}$

Enhanced model:

Minimise

$d_{\text {WEIGHTED }} /$ cycle $=w \cdot d_{\text {VEH }} /$ cycle $+(1-w) \cdot d_{\text {PED }} /$ cycle

where:

$d_{V E H} /$ cycle - the value of vehicle delays in sec/vehicle/cycle;

$d_{P E D} /$ cycle - the value of pedestrian delays in sec/pedestrian/cycle;

$d_{\text {WEIGHTED }} /$ cycle - the weighted value of vehicle and pedestrian delays, in sec/traveller/cycle,

$w$

- the relative weight assigned to vehicle delays;

$j$

$-1,2, \ldots, J_{A}$, number of intersections in the area $A$ street network;

$k$ $-1,2, \ldots, K_{j}$, number of approaches of intersection $j$.

The weight $\mathrm{w}$ in Equation 10 reflects relative importance assigned to vehicle delays to determine optimal signal timing plans with the objective to yield the lowest level of weighted delays per traveller per cycle. Practically, the choice of a weighting factor depends on the traffic management authority's policy where relative weights of vehicle and pedestrian delays could change by the target area for optimal signal timing design and by the period of the day. Without loss of generality, the relative importance of vehicle delays in calculating weighted vehicle and pedestrian delays can be altered from $100 \%$ to 
$10 \%$. For network-wide signal timing optimisation, the base and enhanced models are separately applied with varying weighting combinations.

Figure 1 illustrates the model execution process. As seen in the above framework, iterative computations are conducted progressively from the $1^{\text {st }}$ hour to the $24^{\text {th }}$ hour of the daily analysis period to handle interactions of vehicular traffic only or vehicle and pedestrian traffic jointly expected to enter individual intersections with signal timing plans designed in each hour. The vehicular traffic details in terms of autos, trucks, and buses for through, left-turn, and right-turn movements along different intersection approach in a second-by-second time interval are generated by executing a regional travel demand forecasting model that could readily handle interactions of assigned traffic and travel time with given signal timing plans and their updates. The fine-grained vehicular traffic details are aggregated into hourly vehicular traffic volumes, coupled with hourly pedestrian counts extracted from external resources, to derive the optimal signal timing plans for each hour of the 24-hour period.

Using signal timing plans for AM, PM, and rest of day periods currently deployed in the field as inputs, the regional travel demand forecasting model could be executed to predict vehicular traffic volumes hour-by-hour for the 24-hour period. Based on the predictive vehicular traffic and pedestrian crossing traffic using all intersections in the network in the first hour, the cycle lengths of signal timing plans could be computed. Fixed offsets for adjacent intersections could be determined according to their spacing and average vehicle speed in between them. To ensure signal coordination, cycle lengths for all intersections in the network are constrained to be identical or with one-half cycle length. Next, green splits corresponding to various phases of signal cycles designated to individual intersections in the network could be adjusted to achieve the lowest level of vehicle delays per vehicle per cycle or weighted vehicle and pedestrian delays per traveller per cycle for the entire network. The cycle lengths, offsets, and green splits are essential components of the optimal signal timing plans.

Compared with the initial signal timing plans for the first hour, the optimal signal timing plans for the first hour achieving the lowest level of delays per traveller may trigger re-routing or alter the intersection arrival time for some vehicular travellers. In this respect, the optimal signal timing plans for the first hour could be used to rerun the regional travel demand model to update vehicular traffic predicted using the initial signal timing plans from the $2^{\text {nd }}$ hour onward until the $24^{\text {th }}$ hour of the day. Next, the updated predictive vehicular traffic along with pedestrian traffic estimates for the second hour could be utilised to refine the initially designed signal timing plans for the second hour to establish the optimal signal timing plans for the second hour. Likewise, iterative calculations could be progressed from the $3^{\text {rd }}$ hour to the $24^{\text {th }}$ hour of the day to eventually derive network-wide optimal signal timing plans in each hour of the daily analysis period.

\section{COMPUTATIONAL STUDY}

The street network of the densely populated Chicago central business district (CBD, Chicago, USA) is selected to apply the base and enhanced models for network-wide intersection signal timing optimisation, respectively. For the enhanced model application, varying weighting combinations are considered for computing the weighted vehicle and pedestrian delays. As seen in Figure 2, the study area covers four parts, which are the CBD core of Chicago Loop as subarea 1; north of Loop as subarea 2; immediate west of Loop as subarea 3 ; and near west of Loop as subarea 4 that respectively contain 143, 333, 76, and 269 signalised intersections, adding to a total of 821 intersections.

\subsection{Data preparation}

The underlying efforts begin with obtaining the Chicago regional travel demand forecasting model to help generate predictive vehicular traffic utilising intersections in the study area network, collecting data on pedestrian crossing counts to derive pedestrian traffic estimates, and soliciting details of intersection signal timing plans currently in use. Next, MATLAB scripts as outlined in Figure 1 are developed for applying the proposed base and enhanced models for intersectional signal timing optimisation. Finally, the regional demand model is interfaced with the computer scripts to facilitate executing the two sets of models in succession to progressively generate details of predictive vehicular traffic and develop optimal signal timing 


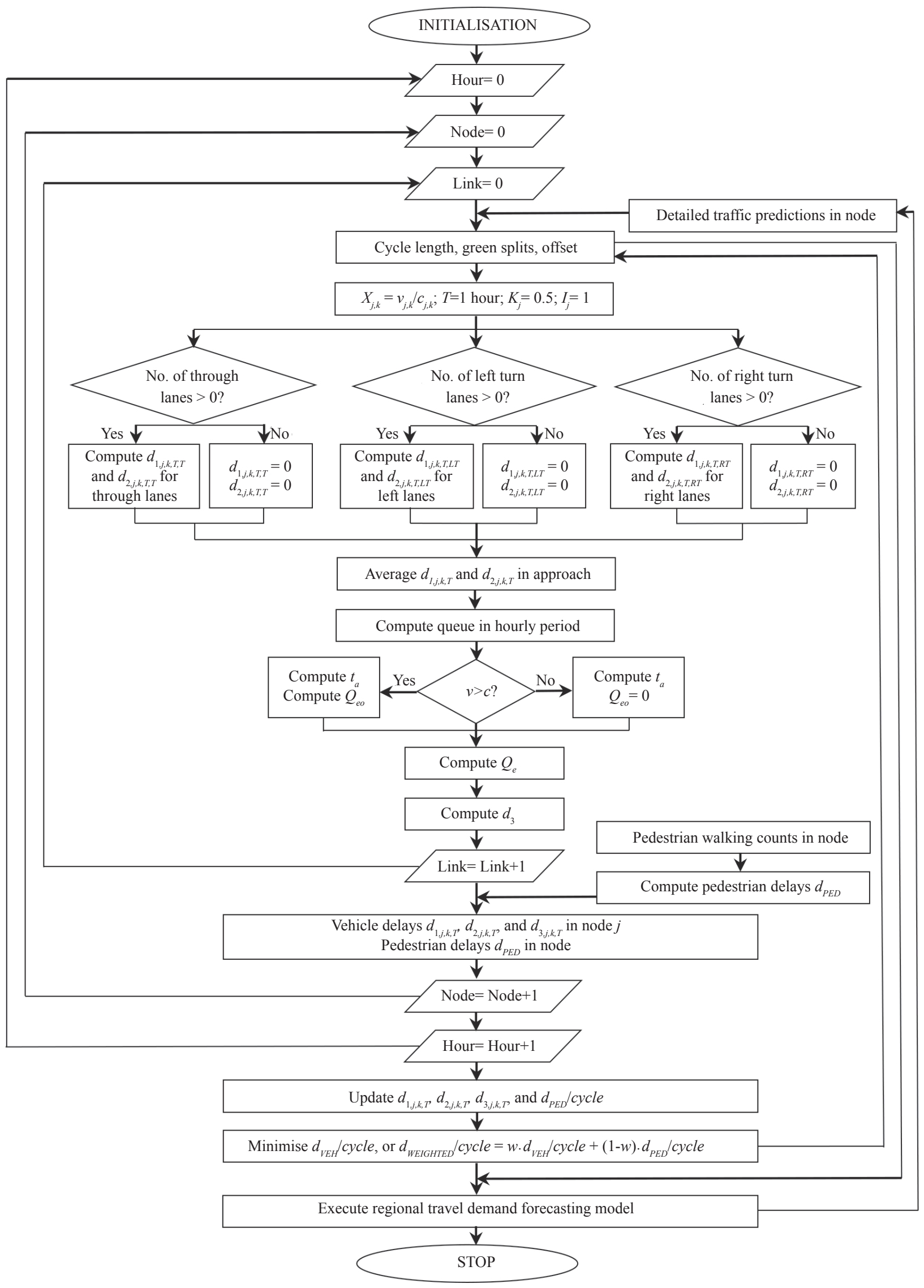

Figure 1 - Computational process of progressive daily network-wide signal timing optimisation 


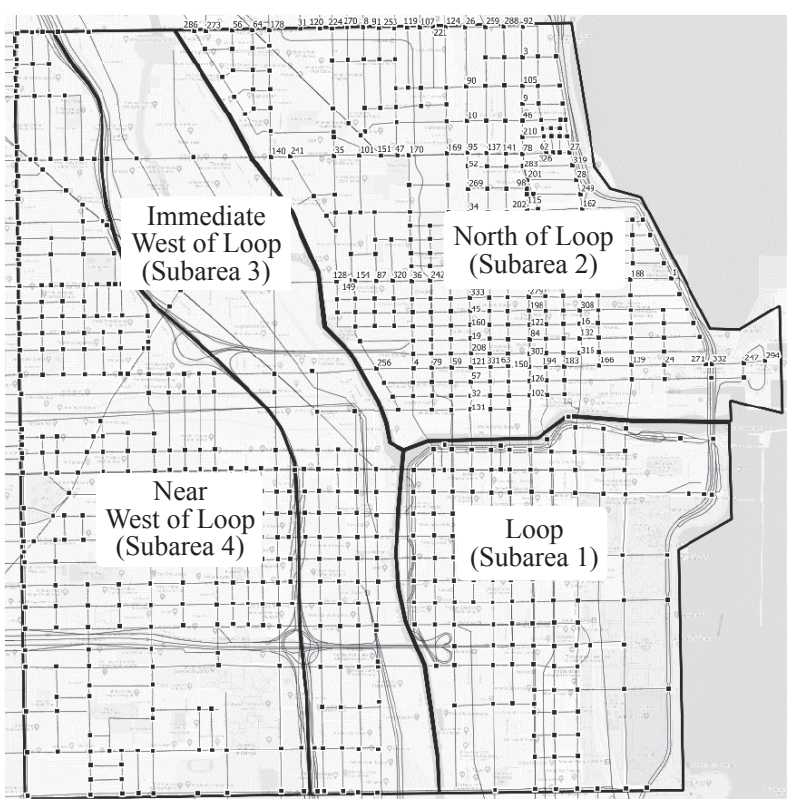

Figure 2 - Illustration of the Chicago CBD street network for intersection signal timing optimisation

plans for intersections in the study area network to achieve minimised delays per traveller per cycle by hour of the day.

\section{Predictive vehicular traffic data}

Data on hourly vehicular traffic predictions is essential to implement the base and enhanced models in the proposed methodology for network-wide signal timing optimisation. For each round of signal timing optimisation, the Chicago model developed based on the TRANSIMS toolbox as the next generation tool for transportation planning, traffic operations, and emergency management analyses in the Chicago metropolitan area is employed to progressively derive high fidelity data on vehicular traffic predictions aggregated into data on hourly predictive vehicular traffic utilising intersections in the study area network.

As background information, the Chicago model covers over 10,000 square miles of Chicago metropolitan area in northeastern Illinois, USA that contains 1,962 traffic analysis zones (TAZs). In a typical weekday, 28.5 million person-trips are produced, which could be classified by travel purposes of Home-Based Work (HBW), Home-Based Other (HBO), Non-Home-Based (NHB), airport trips, external trips, light truck trips, mid-sized truck trips, and large-sized truck trips with corresponding hourly diurnal distributions. In the CBD area, 3.64 million daily person-trips are made, equivalent to $12.8 \%$ of total trips in the metropolitan area. The Chicago model also contains multimodal regional transpor- tation network details in terms of connectivity, geometrics, and operations control of highway network nodes and links; transit routes, stops and stations, and operational schedules in the metropolitan area; and pedestrian walkways in the $\mathrm{CBD}$ area.

Calibration and validation of the Chicago model were successfully completed in 2012 using field data on traffic volumes, speeds, and travel times by travel lane collected from over 800 continuous freeway traffic counting stations in the metropolitan area and 1,200 urban intersection counting locations in the city of Chicago, USA. Approximately one-half of field data was used for model calibration involving adjustments of global and local parameters of route choice and driver behaviour models and refinements of origin-destination (O-D) trips in the Chicago metropolitan area for model fine-tuning to match predicted traffic with field traffic data collected on link-specific volumes, speeds, and travel times. The remaining portion of field data was utilised for model validation via quantitative assessment of model results using such measures as Geoffrey E. Havers (GEH) values and confidence intervals, as well as a qualitative evaluation of reasonableness checks on top O-D travel paths assigned to travellers. For more details, see Li et al. [17].

\section{Pedestrian count data}

Pedestrian walking counts are crucial in applying the enhanced model to develop optimal signal timing plans with the objective of minimising weighted vehicle and pedestrian delays. Pedestrian count data associated with the study area comes from a pedestrian traffic study administered by the city of Chicago in 2007. Relying on 510 counting locations, the study counted over three million pedestrians walking in either direction of sidewalks within the study area from 7:45 AM to 5:45 PM for 10 hours. An annual pedestrian traffic growth rate of one percent is used to update pedestrian counts to keep consistency with the time period of the forecasted vehicular traffic.

\section{Initial signal timing plan data}

For the 821 intersections in the study area, details of intersection signal timing plans initially used in the field are obtained from the city of Chicago, USA.

\subsection{Model application}

\section{MATLAB scripts for executing the signal timing optimisation process}


MATLAB scripts are developed to apply the iterative computational process of signal timing optimisation as outlined in Figure 1. The scripts are concerned with modules for data handling, delay calculation, and signal timing optimisation. The data handling module imports and exports data on vehicle volumes from and to the Chicago model, and intersection signal timing plans before and after optimisation, as well as importing data on pedestrian traffic for analysis. The delay calculation module conducts vehicle delay estimation using the base model, and weighted vehicle and pedestrian delay estimation using the enhanced model as Equations 9 and 10 , respectively. The signal timing optimisation module renders adjustments of green splits of signal timing plans to minimise the level of average delays for travellers utilising intersections in the study area.

\section{Results}

Table 1 lists average hourly vehicle volumes entering signalised intersections in the street networks of each subarea and the entire study area before and after network-wide signal timing optimisation, along with hourly vehicle volumes associated with several signalised intersections in the subarea 2 network as labelled in Figure 1. The average daily vehicle volumes per intersection after network-wide signal timing optimisation reduced by $3.5-7.6 \%$ for signalised intersections in the street networks of subareas 1,2 , and 4 , and increased by $6.0 \%$ for signalised intersections in subarea 2 network. Whereas the average daily vehicle volumes per intersection after network-wide signal timing optimisation for all signalised intersections in the entire study area network remain to be steady, which decreased marginally by $2.0 \%$. The findings suggest that network-wide signal timing optimisation would lead to traffic redistribution from one subarea network to the other, while keeping the total trips using the entire study area stable.

Table 2 summarises computational study results. The effectiveness of signal timing optimisation is measured by percentage reductions in vehicle delays measured in seconds per vehicle per cycle, or reductions in weighted vehicle and pedestrian delays measured in seconds per traveller per cycle. Negative values are indicative of positive effects on delay reductions because of network-wide intersection signal timing optimisation. For the base model application, mixed results are obtained de- pending on the subareas being selected for intersection signal timing optimisation. If only selecting one subarea for network-wide signal timing optimisation, subarea 2 or 4 is the best candidate which could achieve delay reductions by $4 \%$ or $3 \%$. With multiple subareas considered, delay reductions are achieved if both subareas 2 and 4 are included into signal timing optimisation, the options are subareas 2 and 4, subareas 1, 2, and 4, subareas 2,3, and 4, and subareas 1,2,3, and 4 .

When network-wide signal timing optimisation is conducted using the enhanced model, the effectiveness of delay reductions is highly sensitive to combinations of relative weights assigned to vehicle and pedestrian delays. Intersection signal timing optimisation is effective in delay reductions when relative weights of vehicle delays fall in the range of $40 \%-80 \%$, most preferably in the range of $70 \%-80 \%$. With one, two, three, and four subareas chosen for network-wide signal timing optimisation, the highest levels of delay reductions could reach $14 \%, 13 \%, 11 \%$, and $9 \%$, respectively.

\section{Discussion}

The analysis results are not unexpected. Subarea 1 is commonly called the Chicago Loop that stands as the largest employment centre in the entire Chicago metropolitan area, which attracts and produces extensive trips to and from the subarea, leading to high demand of external-internal, internal-external, and internal-internal vehicle and pedestrian travel. Subarea 3 is located west of subarea 1 bounded by I-94 in the west and Chicago River in the east. The east-west arterial streets of subarea 3 not only accommodate external-internal, internal-external, and internal-internal vehicular traffic for the subarea but also serve as the feeder roads for vehicular traffic entering and exiting subarea 1 . This creates high volumes of vehicular traffic within the subarea. Compared with intersections in subareas 2 and 4, the degrees of saturation of intersections in subareas 1 and 3 are potentially higher because of higher volumes of vehicle and pedestrian traffic especially in subarea 1 . The vehicle-to-vehicle, vehicle-to-pedestrian, and pedestrian-to-pedestrian interactions in the two subareas are also more intensive. This leaves less room to further mitigate delays at intersections in the two subareas utilising signal timing optimisation. Conversely, the comparatively lower volumes of vehicle and pedestrian traffic in subareas 2 and 4 cou- 


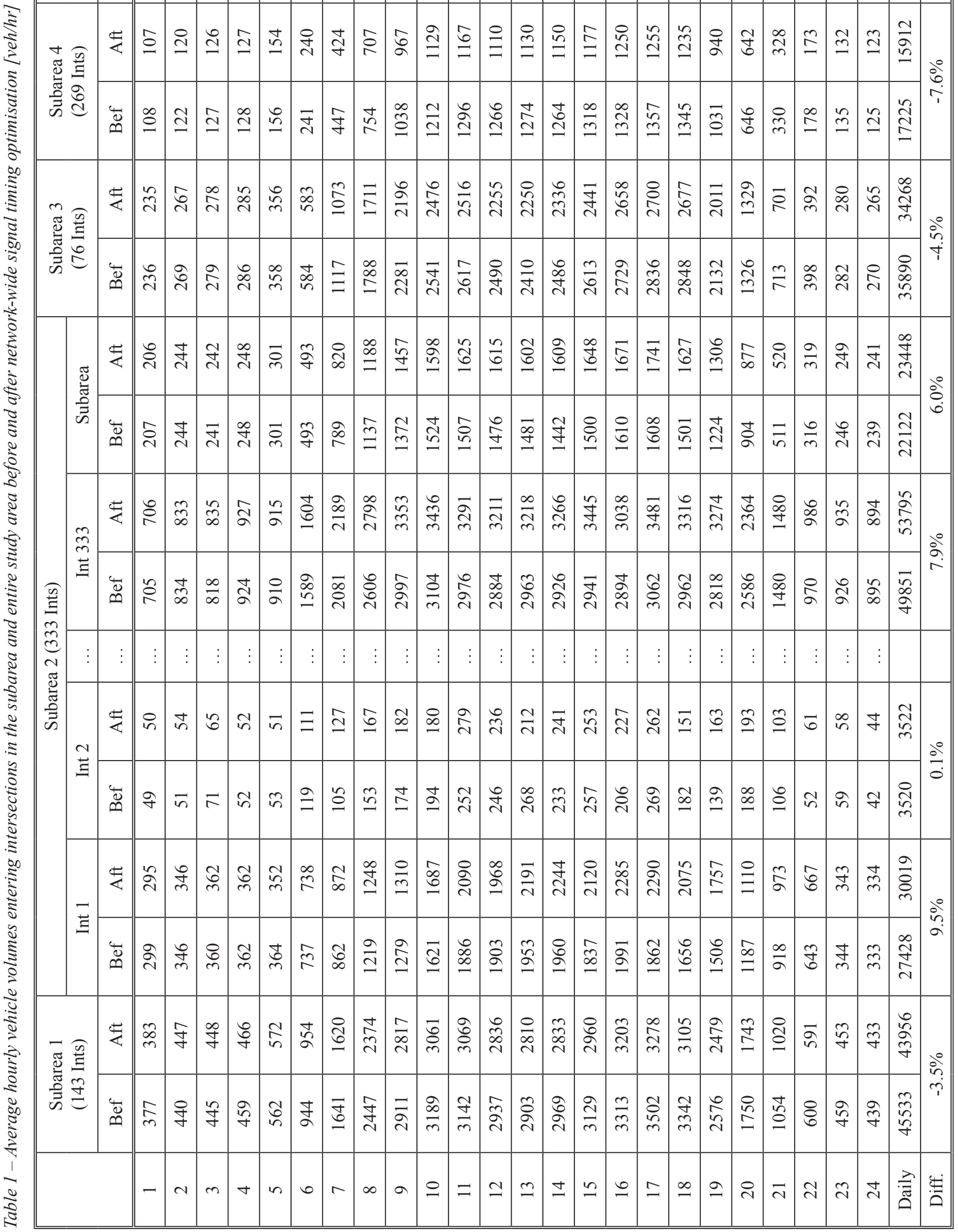

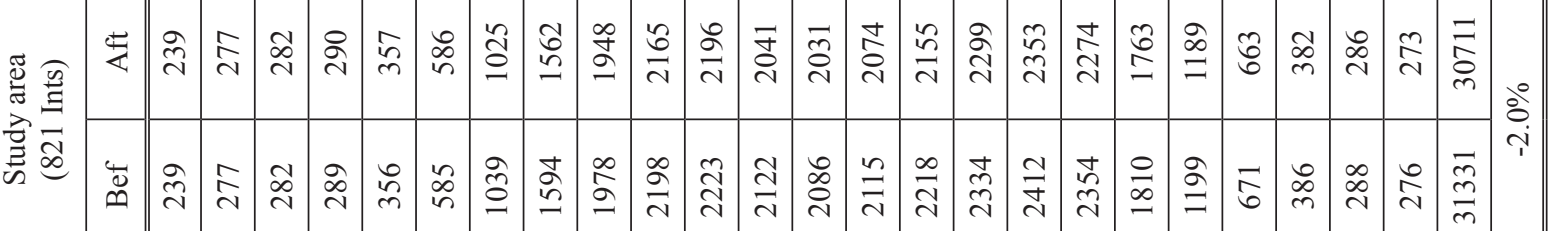


Terraza M, Zhang J, Li Z. Intersection Signal Timing Optimisation for an Urban Street Network to Minimise Traffic Delays

Table 2 - Effectiveness of network-wide signal timing optimisation for different subarea combination scenarios

\begin{tabular}{|c|c|c|c|c|c|c|c|c|c|c||}
\hline \multirow{3}{*}{ Subarea } & \multicolumn{9}{|c|}{ Reductions in average delays } \\
\cline { 2 - 12 } & \multirow{2}{*}{ Base model } & \multicolumn{9}{|c|}{ Enhanced model (Relative weight of vehicle delays, $w$ ) } \\
\cline { 2 - 12 }$y$ & $90 \%$ & $80 \%$ & $70 \%$ & $60 \%$ & $50 \%$ & $40 \%$ & $30 \%$ & $20 \%$ & $10 \%$ \\
\hline \hline 1 & $7 \%$ & $15 \%$ & $-4 \%$ & $0 \%$ & $5 \%$ & $7 \%$ & $8 \%$ & $10 \%$ & $11 \%$ & $12 \%$ \\
\hline 2 & $-4 \%$ & $7 \%$ & $-14 \%$ & $-10 \%$ & $-8 \%$ & $-7 \%$ & $-5 \%$ & $-2 \%$ & $-1 \%$ & $21 \%$ \\
\hline 3 & $4 \%$ & $10 \%$ & $-10 \%$ & $-6 \%$ & $-2 \%$ & $0 \%$ & $2 \%$ & $6 \%$ & $7 \%$ & $6 \%$ \\
\hline 4 & $-3 \%$ & $7 \%$ & $-7 \%$ & $-5 \%$ & $-5 \%$ & $-3 \%$ & $-1 \%$ & $4 \%$ & $6 \%$ & $3 \%$ \\
\hline 12 & $0 \%$ & $9 \%$ & $-11 \%$ & $-7 \%$ & $-4 \%$ & $-3 \%$ & $-1 \%$ & $1 \%$ & $3 \%$ & $19 \%$ \\
\hline 13 & $6 \%$ & $13 \%$ & $-6 \%$ & $-2 \%$ & $2 \%$ & $5 \%$ & $6 \%$ & $9 \%$ & $10 \%$ & $10 \%$ \\
\hline 14 & $0 \%$ & $10 \%$ & $-6 \%$ & $-4 \%$ & $-1 \%$ & $0 \%$ & $2 \%$ & $6 \%$ & $8 \%$ & $6 \%$ \\
\hline 23 & $-2 \%$ & $8 \%$ & $-13 \%$ & $-10 \%$ & $-7 \%$ & $-6 \%$ & $-4 \%$ & $-1 \%$ & $1 \%$ & $18 \%$ \\
\hline 24 & $-3 \%$ & $7 \%$ & $-11 \%$ & $-8 \%$ & $-7 \%$ & $-5 \%$ & $-3 \%$ & $1 \%$ & $2 \%$ & $13 \%$ \\
\hline 34 & $-1 \%$ & $8 \%$ & $-8 \%$ & $-6 \%$ & $-4 \%$ & $-2 \%$ & $0 \%$ & $4 \%$ & $6 \%$ & $3 \%$ \\
\hline 123 & $0 \%$ & $10 \%$ & $-11 \%$ & $-7 \%$ & $-4 \%$ & $-2 \%$ & $-1 \%$ & $2 \%$ & $3 \%$ & $17 \%$ \\
\hline 124 & $-1 \%$ & $8 \%$ & $-9 \%$ & $-7 \%$ & $-4 \%$ & $-3 \%$ & $-1 \%$ & $2 \%$ & $4 \%$ & $13 \%$ \\
\hline 134 & $1 \%$ & $10 \%$ & $-7 \%$ & $-4 \%$ & $-2 \%$ & $0 \%$ & $2 \%$ & $6 \%$ & $8 \%$ & $6 \%$ \\
\hline 234 & $-2 \%$ & $7 \%$ & $-11 \%$ & $-8 \%$ & $-6 \%$ & $-5 \%$ & $-3 \%$ & $1 \%$ & $3 \%$ & $12 \%$ \\
\hline 1234 & $-1 \%$ & $9 \%$ & $-9 \%$ & $-6 \%$ & $-4 \%$ & $-3 \%$ & $-1 \%$ & $3 \%$ & $4 \%$ & $12 \%$ \\
\hline
\end{tabular}

pled with street networks with similar capacities offer a greater potential for reducing intersection delays in the two subareas.

Comparing the two models for network-wide signal timing optimisation, the base model could be considered a special case of the enhanced model by assigning the relative weight of vehicle delays as $100 \%$ in the calculation of weighted vehicle and pedestrian delays. Although subareas 2 and 4 are desirable candidates to deploy signal timing optimisation, the use of the base model is less favourable than the enhanced model in that the optimal signal timing plans developed by the base model exclud- ing pedestrian delay considerations will likely cause excessive pedestrian delays, especially for subarea 2 with high volumes of pedestrian traffic.

Figures $3 a$ and $3 b$ present intuitive results of delay reductions after signal timing optimisation for all possible subarea combinations and most desirable subarea combinations using the base model and the enhanced model, respectively.

As seen in Figure $3 a$, signal timing optimisation is not guaranteed to be effective in achieving intersection delay reductions for all possible combinations of subareas in the study area if minimising vehicle delays is the objective as the base model to develop

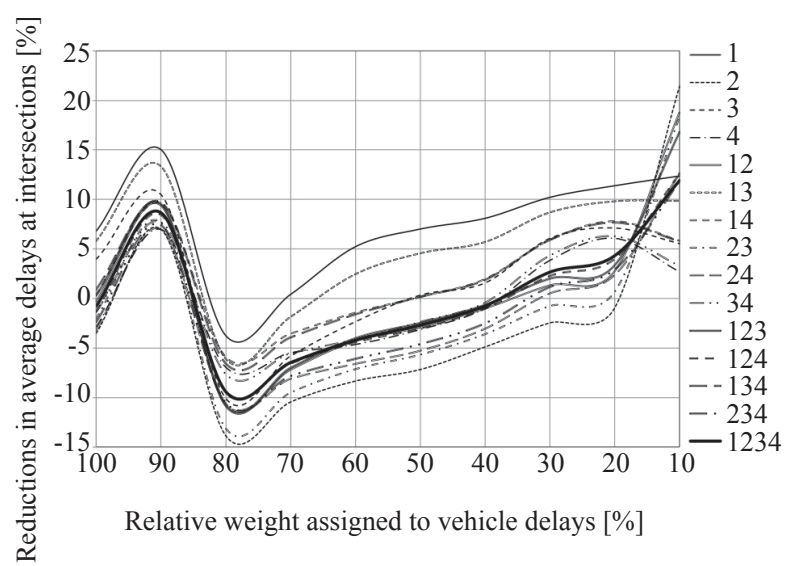

a) All possible subarea combinations

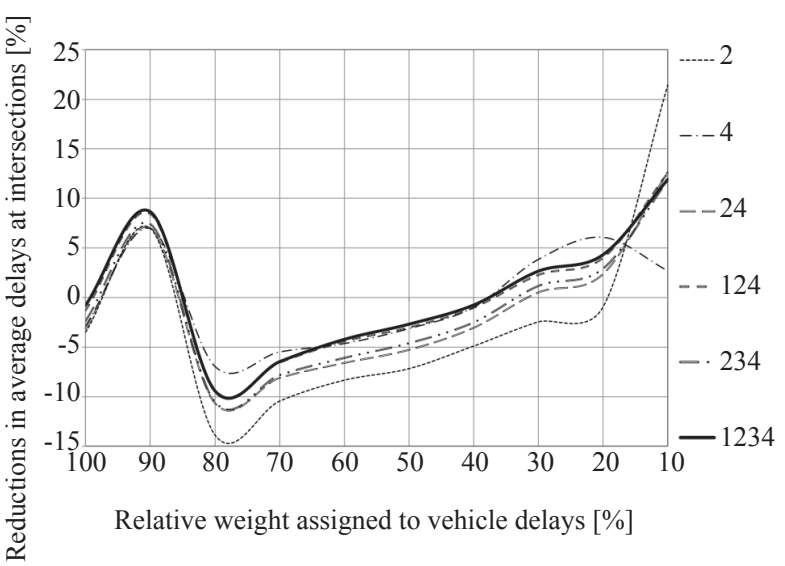

b) Most desirable subarea combinations

Figure 3 - Graphic representation of the effectiveness of network-wide intersection signal timing optimisation 
the optimal signal timing plans. By simultaneously considering vehicle and pedestrian delays and striving for achieving the minimum level of weighted delays as the objective of the enhanced model, the effectiveness of signal timing optimisation is sensitive to weighting combinations for vehicle and pedestrian delays. For all possible subarea combinations, signal timing optimisation is generally effective when the relative weights assigned to vehicle delays are in the range of $70 \%-85 \%$. The extent of reductions in delays measured in seconds per traveller per cycle could be as high as $15 \%$. When relative weights of vehicle delays are assigned to be higher than $85 \%$, signal timing optimisation is likely to increase delays by $5 \%-15 \%$. When relative weights of vehicle delays decrease from $70 \%$ to $20 \%$, signal timing optimisation is expected to trigger steady increases of delays by up to $11 \%$. When relative weights of vehicle delays are further decreased from $20 \%$ to $10 \%$, signal timing optimisation becomes ineffective for all possible subarea combinations with which the highest level of delay increases could exceed $20 \%$.

Figure $3 b$ shows the effectiveness of network-wide signal timing optimisation for the most desirable subarea combinations, which include options of subarea 2, subarea 4 , subareas 2 and 4, subareas 1 , 2 , and 4 , subareas 2,3 , and 4 , and subareas of 1 , 2,3 , and 4 of the study area combined. In comparisons with findings depicted in Figure $3 a$, a similar but more consistent trend is revealed. In general, signal timing optimisation is effective in achieving intersection delay reductions for all desirable subarea combinations if vehicle delays are minimised as the base model. The percentage reductions in vehicle delays measured in seconds per vehicle per cycle could reach $2-4 \%$. With weighted vehicle and pedestrian delays minimised according to the enhanced model, signal timing optimisation is effective when the relative weights assigned to vehicle delays are in the range of $38-85 \%$. Moreover, the highest levels of delay reductions ranging from $7.5 \%$ to $15 \%$ are achieved for all desirable subarea combinations using a weighting split of $78 \%$ and $22 \%$ for vehicle and pedestrian delays. When relative weights of vehicle delays vary from $85 \%-98 \%$, signal timing optimisation is likely to increase delays where the worst case occurs when the relative weight of vehicle delays is assigned as $92 \%$, leading to an increase in delays by $8 \%$. When relative weights of vehicle delays decrease from
$38 \%$ to $20 \%$, signal timing optimisation is expected to trigger steady delay increases by up to $7 \%$. When further decreasing relative weights of vehicle delays from $20 \%$ to $10 \%$, signal timing optimisation becomes ineffective again and the delay increases could exceed $20 \%$.

\section{SUMMARY AND CONCLUSION}

This study has proposed a methodology for network-wide intersection signal timing optimisation over a 24-hour daily period. The objective is to achieve the lowest level of delays for each traveller by dynamically altering green splits of signal timing plans designed for individual intersections in the network hour-by-hour in response to varying vehicle and pedestrian traffic entering the intersections. Two models have been introduced for delay calculation in the optimisation formulation, which aim to minimise vehicle delays per driver and minimise weighted vehicle and pedestrian delays per traveller calculated according to the 2010 HCM method. The relative weights for vehicle and pedestrian delays can be adjusted in the range of $10 \%-100 \%$. The hourly vehicular traffic is derived by progressively executing a regional travel demand forecasting model capable of handling interactions between dynamically predicted traffic and intersection signal timing plans. Predictions of vehicular traffic entering approaches of individual intersections in the network are carried out in alternation with the design of signal timing plans in consecutive time intervals. This helps derive optimal signal timing plans by the hour of the day and obtain high-fidelity predictive vehicular traffic on a second-by-second basis that could be aggregated into hourly predictive vehicular traffic. MATLAB scripts have been created to facilitate methodology application.

A computational experiment targeting the Chicago CBD street network has been conducted for network-wide intersection signal timing optimisation. The study area is generally classified into four subareas that contain 821 signalised intersections. Of the two models proposed for delay calculations, the base model that computes vehicular delays only is essentially a special case of the enhanced model that calculates weighted vehicle and pedestrian delays by assigning a relative weight of $100 \%$ to vehicular delays. 
According to model execution results, delay reductions are found to be sensitive to relative weights assigned to vehicle and pedestrian delays calculated in the objective function of the enhanced model for network-wide intersection signal timing optimisation. Also, not all four subareas are effective in achieving delay reductions. This seems to suggest that network-wide signal timing optimisation could be potentially effective if degrees of saturation of intersections in a street network are comparatively low where the remaining intersection capacities could still accommodate a significant amount of traffic. In this case, fine-tuning of signal timing plans for intersections in one or more subarea networks could help improve the efficiency of intersection capacity utilisation with delay reductions.

The application of the enhanced model with vehicle and pedestrian delays calculated using the 2010 HCM method for network-wide intersection signal timing optimisation has confirmed that relative weights assigned to the two categories of delays as the objective to be minimised, and degrees of saturation of intersections in the study area network are two factors affecting the effectiveness of delay reductions. Network-wide signal timing optimisation is not always effective in reducing delays for all possible subarea combinations. Thus, the proposed methodology could be used by municipalities to identify alternative subarea combinations potentially effective in delay reductions from network-wide signal timing optimisation and to prioritise them for real-world deployments accordingly.

The computational study has revealed that the proposed methodology is useful in identifying subareas that might benefit from intersection signal timing optimisation for delay deductions, quantifying the benefits, and prioritising the best option for field deployments. However, extensive efforts are needed in data collection, preparation, and computation, especially iterative analysis of vehicular traffic predictions, delay estimation, and signal timing optimisation. Therefore, the proposed methodology may be adopted for real-world applications by large municipalities with rich data resources of travel demand, and traffic operations and control, as well as budget strength for field deployments that typically require upgrading and replacing hardware and software of intersection control.

\section{DATA AVAILABILITY}

Some data, models, or code that support the findings of this study are available from the corresponding author upon reasonable request.

\section{ACKNOWLEDGMENTS}

The authors are grateful for the assistance of transportation agencies in the Chicago metropolitan area for data collection, processing, and computational analysis. Additional thanks are extended to publication support of NNSFC 71871029, CHD 300102219306, and CHD 300102218404.

\section{MANEL TERRAZA}

Correo electrónico: manel.terraza@gmail.com JI ZHANG ${ }^{2}$

Correo electrónico: jzhan121@hawk.iit.edu

ZONGZHI LI, Doctor en Filosofía ${ }^{2}$

(Autor correspondiente)

Correo electrónico: lizz@iit.edu

${ }^{1}$ Departamento de Ingeniería Civil

Universitat Politècnica de Catalunya

Barcelona, España

2 Departamento de Ingeniería Civil, Arquitectónica

y Ambiental Instituto de Tecnología de Illinois

Chicago, IL 60616, EE.UU

\section{OPTIMIZACIÓN DEL TIEMPO DE LA SEÑAL DE INTERSECCIÓN PARA UNA RED \\ DE CALLE URBANA PARA MINIMIZAR LAS RETRASOS DEL TRÁFICO \\ RESUMEN}

La creciente demanda de viajes que supera la capacidad de transporte disponible, especialmente en las áreas urbanas de los EE. UU., Ha provocado retrasos y congestiones de tráfico más graves. Este estudio propone una metodología para la optimización del tiempo de las señales de intersección para una red de calles urbanas con el objetivo de minimizar los retrasos relacionados con las intersecciones ajustando dinámicamente las divisiones verdes de los planes de tiempo de las señales diseñados para las intersecciones en una red de calles urbanas en cada hora del día en respuesta a la variación del tráfico. entrar en las intersecciones. Se consideran dos opciones en la formulación de optimización, que se refieren a minimizar las demoras de vehículos por ciclo y minimizar las demoras ponderadas de vehiculos y peatones por ciclo calculadas usando el método del Manual de Capacidad de Carreteras (HCM) de 2010. El tráfico vehicular por hora se deriva mediante la ejecución progresiva de un modelo de pronóstico de demanda de viajes regional que podría manejar las interacciones entre los planes de tiempo de señales y el tráfico vehicular previsto que ingresa a las intersecciones, junto con los 
recuentos de cruces de peatones. Se realiza un estudio computacional para la aplicación de la metodología a la red de calles del distrito comercial central (CBD) en Chicago, EE. UU. Se revela que los pesos relativos para calcular las demoras ponderadas de vehículos y peatones, y los grados de saturación en las intersecciones, son factores importantes que afectan la efectividad de la optimización del tiempo de señal en toda la red. Para el estudio actual, las reducciones de retrasos se maximizan utilizando una división de ponderación de 78/22 entre retrasos de vehículos y peatones.

\section{PALABRAS CLAVE}

red urbana; intersección; retraso del vehículo; retraso de peatones; temporización de la señal; mejoramiento.

\section{REFERENCES}

[1] TRB. Highway capacity manual. Transportation Research Board. Washington, D.C.: National Academic Press; 2010.

[2] Li Z. Transportation asset management: Methodology and applications. First Edition. Boca Raton, FL: CRC Press, Taylor and Francis Group; 2018.

[3] Koutsopoulos HN, Habbal M. Effect of intersection delay modeling on the performance of traffic equilibrium models. Transportation Research Part A: Policy and Practice. 1994;28(2): 133-149. DOI: 10.1016/09658564(94)90034-5

[4] Fambro DB, Rouphail NM. Generalized delay model for signalized intersections and arterial streets. Transportation Research Record. 2007;1572: 112-121. DOI: 10.3141/1572-14

[5] Aashtiani HZ, H. Iravani H. Use of intersection delay functions to improve reliability of traffic assignment models. Proceedings of the $14^{\text {th }}$ Annual International EMME/2 Conference, 20-22 October 1999, Chicago, USA. Montreal: INRO Consultants; 1999. p. 20-28. Available from: https://www.academia.edu/2605461/Use_of_intersection_delay_functions_to_improve_reliability_of_traffic assignment_model [Accessed 11th Feb. 2020].

[6] Webster FV. Traffic signals settings. Road Research Laboratory Crowthorne, London, United Kingdom. Report number: 39, 1958. Available from: https://www.sinaldetransito.com.br/artigos/traffic_signals_webster.pdf [Accessed 2nd Mar. 2020].

[7] INRO. EMME/2 user's manual. Software Release 7. INRO Consultants; 1994. Available from: https:/www. inrosoftware.com/en/products/emme/ [Accessed 5th Mar. 2020].
[8] Liu GP, Zhai RP, Pei YL. A calculating method of intersection delay under signal control. Proceedings of the 2007 IEEE Conference on Intelligent Transportation Systems, 30 Sep. - 3 Oct. 2007, Bellevue, WA. New York: Institute of Electrical and Electronics Engineers (IEEE); 2007. p. 648-653. DOI: 10.1109/ITSC.2007.4357783

[9] Mazloumi E, Moridpour S, Mohsenian H. Delay function for signalized intersections in traffic assignment models. Urban Planning and Development. 2010;136(1): 67-74. DOI: 10.1061/(ASCE)0733-9488(2010)136:1(67)

[10] Wolshon B, Taylor WC. Analysis of intersection delay under real-time adaptive signal control. Transportation Research Part C: Emerging Technologies. 1999;7(1): 5372. DOI: 10.1016/S0968-090X(99)00011-X

[11] Lowrie PR. The Sydney coordinated adaptive traffic system- principles, methodology, algorithms. Proceedings of the International Conference on Road Traffic Signaling, 30 Mar. - 1 Apr. 1982, London, United Kingdom. London: Institution of Electrical Engineers; 1982. p. 67-80. Available from: https://pascal-francis.inist.fr/ $\mathrm{vibad} /$ index.php? action=getRecordDetail\&idt=PASCAL82X0330853 [Accessed 6th Mar. 2020].

[12] Quiroga CA, Bullock D. Measuring control delay at signalized intersections. Transportation Engineering. 1999;125(4): 271-280. DOI: 10.1061/(ASCE)0733-947X (1999)125:4(271)

[13] Li Z, Li N, Liu F. An effective calculating method of signalized intersection delay. Proceedings of the 2009 International Conference on Digital Image Processing, 7-9 March 2009, Bangkok, Thailand. New York: Institute of Electrical and Electronics Engineers (IEEE); 2009. p. 211-215. DOI: 10.1109/ICDIP.2009.41

[14] Zhu Z, et al. A simplified real-time road network model considering intersection delay and its application on vehicle navigation. Applied Mechanics and Materials. 2011;58-60: 1959-1965. DOI: 10.4028/www.scientific. net/AMM.58-60.1959

[15] Qiao F, Yi P, Yang H, Devarakonda S. Fuzzy logic based intersection delay estimation. Mathematical and Computer Modelling. 2002;36(11/13): 1425-1434. DOI: 10.1016/S0895-7177(02)00298-4

[16] Roshandeh AM, et al. New methodology for intersection signal timing optimisation to simultaneously minimise vehicle and pedestrian delays. Transportation Engineering. 2014;140(5): 04014009. DOI: 10.1061/(ASCE) TE.1943-5436.0000658

[17] Li Z, et al. Development and application of the TRANSIMS toolbox for transportation operations management in and around Chicago central area. Federal Highway Administration, U.S. Department of Transportation. Phase I Final Report, 2012. 